\title{
Model Test on the Vibration Reduction Characteristics of a Composite Foundation with Gravel Cushion under Different Seismic Wave Amplitudes
}

\author{
Yingying Zhao $\mathbb{D}^{\mathbb{1}}{ }^{1,2,3}$ Weiming Gong $\mathbb{D}^{1,2}$ Xianzhang Ling $\mathbb{D}^{1,4}{ }^{3,4}$ Peng Li $\mathbb{D}^{5},{ }^{5}$ Ziyu Wang $\mathbb{D}^{6}$ \\ and Hong Fan $\mathbb{D}^{7}$ \\ ${ }^{1}$ Key Laboratory of Concrete and Prestressed Concrete Structures of Ministry of Education, Southeast University, \\ Nanjing 211189, China \\ ${ }^{2}$ School of Civil Engineering, Southeast University, Nanjing 211189, China \\ ${ }^{3}$ School of Civil Engineering, Harbin Institute of Technology, Harbin 150090, China \\ ${ }^{4}$ School of Civil Engineering, Qingdao University of Technology, Qingdao 266033, China \\ ${ }^{5}$ School of Civil and Architectural Engineering, East China University of Technology, Nanchang 330013, China \\ ${ }^{6}$ School of Ecological Environment, Hainan Tropical Ocean University, Sanya 572022, China \\ ${ }^{7}$ China Nuclear Power Engineering Co., Ltd., Shenzhen 518040, China
}

Correspondence should be addressed to Weiming Gong; wmgong@seu.edu.cn

Received 18 November 2020; Revised 29 November 2020; Accepted 28 January 2021; Published 8 February 2021

Academic Editor: Guangchao Zhang

Copyright $\odot 2021$ Yingying Zhao et al. This is an open access article distributed under the Creative Commons Attribution License, which permits unrestricted use, distribution, and reproduction in any medium, provided the original work is properly cited.

Gravel cushions have been introduced as a practical and efficient seismic isolation technology to ensure the safety of nuclear power plants. This study investigated the seismic isolation effect of a gravel cushion by conducting a series of shaking table tests on a model foundation with a cushion built of three different types of graded aggregates (single-sized $(2-5 \mathrm{~mm})$, two-sized (2-5 mm: $5-10 \mathrm{~mm}=3: 1)$, and continuously graded) under input El Centro seismic waves with three different peak accelerations (0.1 g, $0.2 \mathrm{~g}$, and $0.3 \mathrm{~g}$ ). The testing results showed that the seismic isolation effect of the gravel cushion increased with the peak seismic acceleration. The gravel cushion built with single-sized aggregates had better seismic isolation performance than gravel cushions built with two-sized or continuously graded aggregates. Under input seismic waves with $0.1 \mathrm{~g}$ peak acceleration, the single-sized aggregate gravel cushion still had a seismic isolation effect with a vibration reduction rate of approximately $11.81 \%$, whereas the other two gravel cushions had no effect. Under input seismic waves with peak accelerations of $0.2 \mathrm{~g}$ and $0.3 \mathrm{~g}$, all three gravel cushions had seismic isolation effects with vibration reduction rates of approximately $18.63 \%$ and $17.92 \%$, respectively. An empirical model is proposed for predicting the vibration reduction rate of the cushion. Under input seismic waves with $0.3 \mathrm{~g}$ peak acceleration, the ultimate vibration reduction rate of the gravel cushion fell between $20.44 \%$ and $31.33 \%$. The gravel cushion is an excellent option for nuclear power plant foundations with high requirements for seismic isolation, provided that the required bearing capacity is satisfied.

\section{Introduction}

The seismic design of nuclear power plants is vital for not only the smooth operation of nuclear power equipment but also the safety of the ecological environment and human life in surrounding areas. On March 11, 2011, the Fukushima Daiichi Nuclear Power Plant suffered massive radiation leaks and explosions from an earthquake with a magnitude of 9.1 on the Richter scale. The earthquake hit the Pacific Ocean off the Japanese coast and caused incalculable losses. The technology of the Chinese nuclear power industry has reached an advanced international level. Comprehensive standards and specifications have been established, with very high requirements for the seismic precautionary intensity and foundation performance of nuclear power plants. According to the standard for seismic design of nuclear power plants [1], structures of seismic categories I and II should be built on a bedrock or a subsoil with a shear wave 
velocity greater than $300 \mathrm{~m} / \mathrm{s}$, and the subsoil properties should not have significant nonuniformity [1]. China's nuclear power plants are mostly located in coastal areas and are built on hard bedrock at sites with satisfactory geological conditions. While new nuclear power plants are being constructed to meet the socioeconomic demand, site selection has become a major bottleneck in the development of nuclear power, because some nuclear power plants have to be built at soft-soil sites after comprehensive considerations. This bottleneck presents a technical challenge; namely, natural foundations cannot achieve the required bearing capacity and seismic isolation effect. Therefore, there is a dire need for effective foundation reinforcement and seismic isolation technology.

To improve the bearing capacity and seismic isolation effect, technologies have been developed to build rigid-pile composite foundations that boost high bearing capacity, small settlement, ease of construction, and short lead time [2-7]. Rigid-pile composite foundation is an artificial foundation that consists of piles, foundation, and sand stone cushion with a certain thickness [8]. The piles effectively reinforce the soil layer, and the piles and the soil between the piles concurrently act to bear the load, which improves the bearing capacity. The sand/stone cushion can absorb and dissipate the seismic energy that is transmitted from seismic waves to the superstructure, which prevents resonance and realize seismic isolation and vibration reduction. Cushion seismic isolation technology is applicable to nuclear power plant structures after full demonstration of technical and financial feasibility.

Cushion seismic isolation technology is easy to implement, is cost effective, and has received considerable attention, with significant research achievements. Yang et al. [9] investigated the seismic response of a superstructure-a rigid-pile composite foundation system in a saturated-soft soil site under seismic forces-by conducting centrifuge-shaking table tests. They discovered that the sand cushion between the foundation and the raft served to dissipate the upward-propagating seismic forces, and the cushion's vibration reduction effect increased with the ground motion intensity. Sharma et al. [10] investigated the effect of the cushion in a piled-raft composite foundation on the axial and shear forces on the piles. They discovered that the addition of the cushion markedly reduced the maximum tension of the long-pile head. Hazarika et al. [11] investigated the seismic isolation effect of a caisson foundation protected with a cushion made of scrap tirederived chips by conducting a series of shaking table tests. They determined that the tire-chip cushion performed well in absorbing seismic energy and reducing the seismic load and displacement of the caisson. Tu et al. [12] conducted shaking table tests to investigate a bridge caisson foundation protected with a cushion of either sand or gravel. They determined that the gravel cushion experienced larger displacement than the sand cushion but outperformed the sand cushion in seismic energy absorption and dissipation, had a better seismic isolation effect, and contributed to a faster rate of decrease in the resonant frequency of the foundation.
Significant research on the seismic isolation effect of sand cushions has been conducted. Sand cushions built with single-sized aggregates better reduce vibrations than those built with continuously graded aggregates, and thicker cushions perform better than thinner cushions [13-15]. To improve the seismic isolation effect, thick, single-sized aggregated sand cushions should be employed; however, these cushions are susceptible to sand liquefaction under seismic forces. Because of its satisfactory seismic isolation effect, a gravel cushion can be utilized in nuclear power engineering as the seismic isolation and energy dissipation layer of a nuclear power plant foundation. Since cushions have been adopted as the major means of reinforcing the artificial foundations of nuclear power plants, investigating the seismic isolation performance of gravel cushions has significance in nuclear power engineering and construction.

Research on the seismic isolation effect of a gravel cushion is still in the stage of theoretical analysis and laboratory investigation. Han et al. [16, 17] discovered that the thicknesses of gravel cushions was positively proportional to the seismic isolation performance and that a gravel cushion with a thickness range of 0.2 to $0.3 \mathrm{~m}$ could reduce the acceleration by 10 to $15 \%$. Using the discrete element method, Zhao et al. [18] comparatively investigated the seismic isolation effect of gravel cushions of different thicknesses on the superstructure at different foundation base pressures. They discovered that the gravel cushions effectively reduced the seismic response of the superstructure and the seismic isolation effect increased as the cushion thickness increased but decreased as the foundation base pressure increased. Li et al. [19] conducted a series of horizontal shear tests on cushions made with different materials to quantity the effect of a gravel cushion on the seismic isolation effect of piled-raft foundations. They determined that the energy dissipation capacity of the gravel cushion was less correlated with the internal friction angle of the material but was considerably affected by the vertical load. For a given shear displacement, the energy dissipation capacity of the gravel cushion increased with the vertical load, which was accompanied by increasing shear forces that are transmitted upward to the superstructure. Wu et al. [20] conducted shaking table tests to investigate the seismic isolation effect of rigid-pile composite foundations and discovered that a gravel cushion had good seismic isolation effect.

Studies of composite foundations for nuclear power plants have focused on bearing capacity and settlement and rarely on seismic isolation. Therefore, this study designed a composite foundation for a nuclear power plant and established a system coupling of the piles, soil, gravel cushion, raft, and superstructure. A series of shaking table tests were performed on a model of the system to investigate the seismic isolation performance of gravel cushions that were built with different aggregate gradations, placed at different buried depths, and subjected to different peak accelerations. Our aim was to facilitate the engineering application of gravel cushion seismic isolation technology. 


\section{Test Program}

2.1. Testing Materials. A foundation model was built with a clay that is common in the eastern coastal areas of China and had a water content of $23.52 \%$ and a density of $1.78 \mathrm{~g} / \mathrm{cm}^{3}$. Three cushions were built from construction-grade gravel with three different types of graded aggregates: single-sized $(2-5 \mathrm{~mm})$, two-sized $(2-5 \mathrm{~mm}: 5-10 \mathrm{~mm}=3: 1)$, and continuously graded. The continuous gradation produced wellgraded aggregates with a coefficient of uniformity $\left(C_{\mathrm{u}}\right)$ of 5.02 and a coefficient of curvature $\left(C_{\mathrm{c}}\right)$ of 1.86 (Table 1 and Figure 1). Figure 2 shows photographs of the three different aggregates. Table 2 lists the basic physical properties of the aggregates.

2.2. Testing Devices. An electrohydraulic, servo-driven, three-directional, six-degree-of-freedom earthquake-simulation shaking table at Southeast University was utilized. The shaking table consisted of a specimen-mounting table, hydraulic servo actuation system, simulation control system, and computerized data acquisition and control system (Figure 2(a)). The specimen-mounting table measured $4 \times 6 \mathrm{~m}$, moved in the $x$-direction when actuated, and had a maximum vertical bearing capacity of $30 \mathrm{t}$, maximum horizontal displacement of $\pm 250 \mathrm{~mm}$, maximum horizontal velocity of $600 \mathrm{~mm} / \mathrm{s}$, and maximum horizontal acceleration of $1.5 \mathrm{~g}$.

A model was built for simulating the shear deformation of the soil (Figure 3(b)). The model well simulated the shear deformation of the soil. The model measured 2 (length) $\times 2$ (width) $\times 1.3$ (height) $\mathrm{m}$ and was bounded with a $10 \mathrm{~cm}$ thick container that had a minimum boundary effect. The container inner wall was covered with a $10 \mathrm{~cm}$-thick impermeable sponge layer to waterproof the container and reduce wave reflection from the boundary.

Tests were conducted under unidirectional horizontal excitation. Before testing, a $0.05 \mathrm{~g}$ white noise was input to test the dynamic performance of the system. El Centro seismic waves with peak accelerations of $0.1 \mathrm{~g}, 0.2 \mathrm{~g}$, and $0.3 \mathrm{~g}$ were sequentially input for $50 \mathrm{~s}$ each to test the seismic response behavior of the model. Figure 4 shows the time history of the input seismic wave with a $0.1 \mathrm{~g}$ peak acceleration. The 50-second duration of seismic wave was determined by a time similarity factor of 0.115 .

2.3. Test Model Design. Shaking table tests are mainly employed to investigate the dynamic response characteristics and failure mechanisms of structures under seismic waves. To adequately simulate the seismic response of a real-world structure, the model should be designed with a similarity relationship. In this study, the following basic similarity parameters were applied: length $l$, modulus of elasticity $E$, and acceleration $a$. The model was designed with a geometric similarity ratio of 0.04 according to the bearing capacity of the shaking table and geometric dimensions of the specimen-mounting table; an elastic modulus similarity ratio of 0.3 to ensure that the test model and original structure had consistent material strength; and an acceleration similarity ratio of 3.0 according to the ratio of the maximum acceleration at the specimen-mounting table surface to the maximum applied acceleration.

The model system consisted of piles, soil, cushion, raft, and superstructure (Figure 5). In real-world nuclear power engineering, the superstructure is built on a common raft foundation. The model was designed and constructed as follows. The first step was to build a container to hold the superstructure consisted of a podiums made by organic glass plates $(44.2 \mathrm{~cm}$ in length, $32.8 \mathrm{~cm}$ in width, and $14.8 \mathrm{~cm}$ in height) and a cylindrical reactor made by an aluminum tube $(28.8 \mathrm{~cm}$ in height, $15.2 \mathrm{~cm}$ in diameter, and $0.5 \mathrm{~cm}$ in thickness) (Figure 6(a)), which was bolted to a raft made by aluminum plates with dimensions of $47.6 \times 36.2 \times 3.2 \mathrm{~cm}$ and a weight of $40.076 \mathrm{~kg}$ (Figure 6(b)). The superstructure-raft connection was approximately rigid. Rigid blocks with a total mass of $168.644 \mathrm{~kg}$ were placed into the superstructure container and affixed to the raft (Figure 6(c)). An integrated superstructure-raft structure was constructed (Figure 6(d)).

Circular aluminum tubes with an outer diameter of $2.8 \mathrm{~cm}$, an inner diameter of $2.6 \mathrm{~cm}$, and a length of $60 \mathrm{~cm}$ were utilized as model piles. A total of 12 piles, which were spaced at $9.8 \mathrm{~cm}$ (larger than 3.5 times the pile diameter) in accordance to the "Technical Code for Building Pile Foundation (JGJ 94-2008)" of China and arranged in a $4 \times 3$ matrix, were installed on the soil layer to construct a pile-soil composite foundation.

The gravel cushion, which had a thickness of $5 \mathrm{~cm}$, was constructed with three different aggregate gradations: singlesized, two-sized, and continuously graded. The cushion was buried at two different depths: above the raft and beneath the raft. It is worth pointing out that for cushion placed above the raft, the horizontal displacement of the raft could be limited during horizontal seismic excitations, whereas a relative larger horizontal displacement may occur for the raft above cushion. Such difference could directly affect the seismic isolation effect of gravel cushion. Therefore, it is necessary to compare the two burying patterns of raft in terms of seismic isolation.

The test model was constructed with the following procedure: (1) The layered shear deformation soil model container was bolted to the specimen-mounting table. The container inner wall was covered with a $10 \mathrm{~cm}$-thick, impermeable sponge layer. (2) The container was filled with clay, which was compacted layer by layer to a total height of $1 \mathrm{~m}$ and was allowed to sit for $24 \mathrm{~h}$ for static consolidation before the tests, as shown in Figure 7(a). (3) Piles were mounted into the holes reserved in the compacted clay, which were made by preinstalling piles in the preset arrangement $(4 \times 3)$ while casting the clay (Figure 7(b)). (4) A layer of gravel was cast and compacted, with the surface smoothed and the final thickness measuring $5 \mathrm{~cm}$. (5) The raft was placed horizontally, with its center aligned with that of the pile matrix. The superstructure container was bolted to the raft. Mass blocks were placed in the container and fixed on the raft to integrate the superstructure and raft, as shown in 
TABLE 1: Particle size distribution of continuously graded aggregates.

\begin{tabular}{lccccc}
\hline Particle size (mm) & $10-5$ & $5-2$ & $2-1$ & $1-0.5$ & $0.5-0$ \\
Content (\%) & 21.40 & 73.28 & 4.85 & 0.38 & 0.09 \\
\hline
\end{tabular}

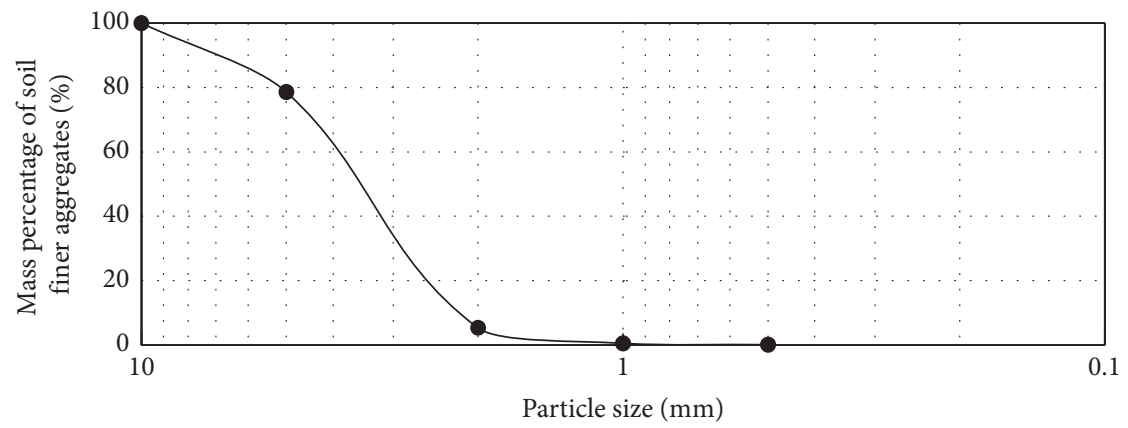

Figure 1: Particle size distribution curve of continuously graded aggregates.

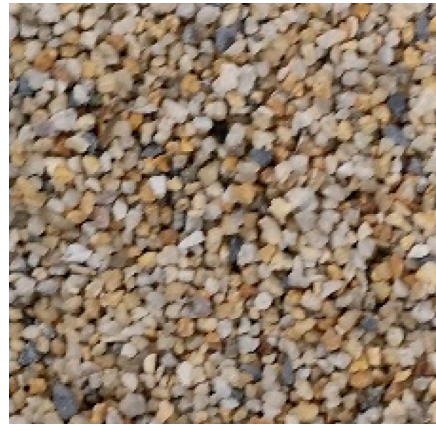

(a)

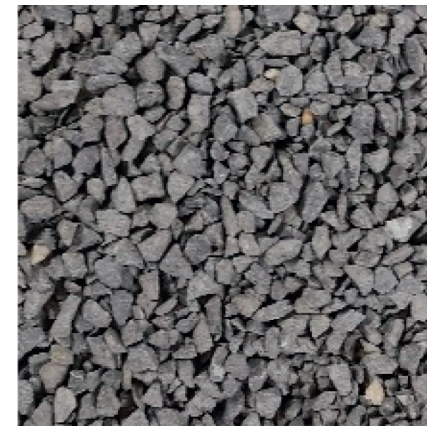

(b)

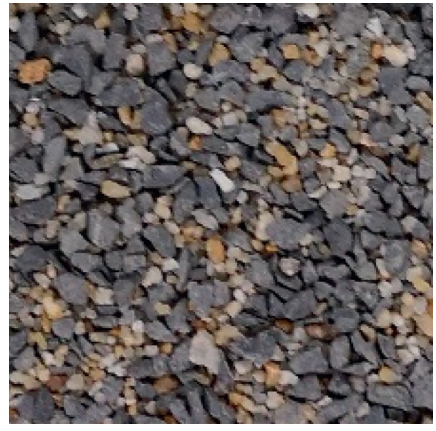

(c)

Figure 2: Three gravel aggregates of different gradations. (a) Single-sized aggregates. (b) Two-sized aggregates. (c) Continuously graded aggregates.

TABLE 2: Physical properties of three gravel aggregates of different gradations.

\begin{tabular}{|c|c|c|c|c|c|}
\hline Aggregate gradation & Particle size $(\mathrm{mm})$ & Minimum dry density $\left(\mathrm{g} / \mathrm{cm}^{3}\right)$ & Maximum dry density $\left(\mathrm{g} / \mathrm{cm}^{3}\right)$ & $\begin{array}{l}\text { Coefficient of } \\
\text { uniformity }\end{array}$ & $\begin{array}{l}\text { Coefficient } \\
\text { of curvature }\end{array}$ \\
\hline Single-sized & $2-5$ & 1.32 & 1.58 & & \\
\hline Two-sized & $2-10$ & 1.35 & 1.66 & & \\
\hline Continuously grade & $0-10$ & 1.36 & 1.68 & 5.02 & 1.86 \\
\hline
\end{tabular}

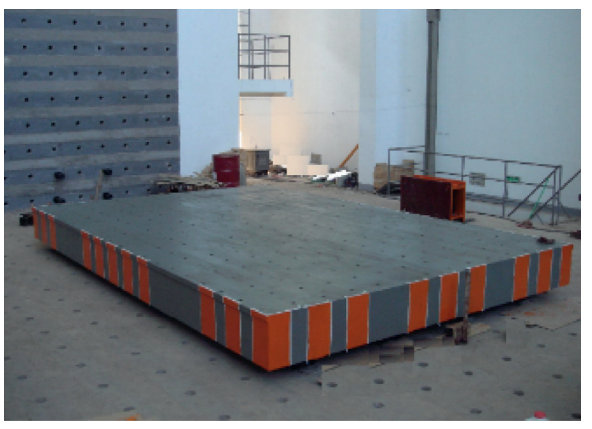

(a)

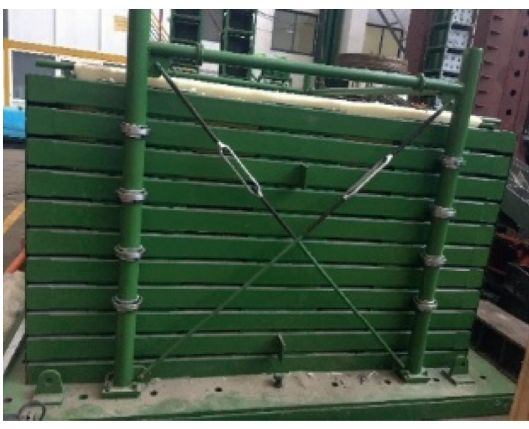

(b)

Figure 3: Shaking table and layered shear deformation model container. (a) Specimen-mounting table $(4 \times 6 \mathrm{~m})$. (b) Model container $(2$ (length) $\times 2$ (width) $\times 1.3$ (height) $(\mathrm{m}) \times 0.1$ (wall thickness) . 


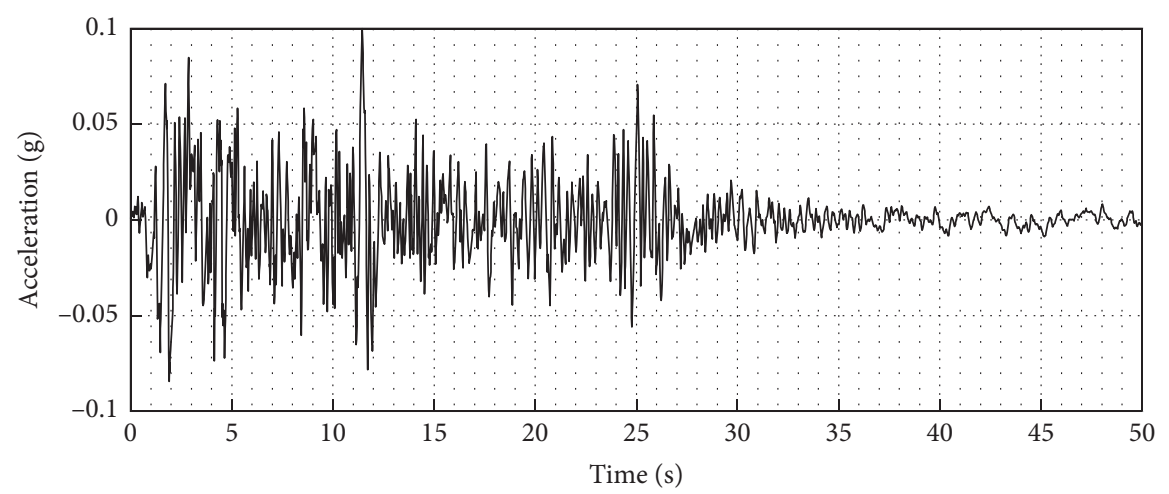

Figure 4: Time history of an El Centro seismic wave input into the shaking table (acceleration $=0.1 \mathrm{~g}$ ).

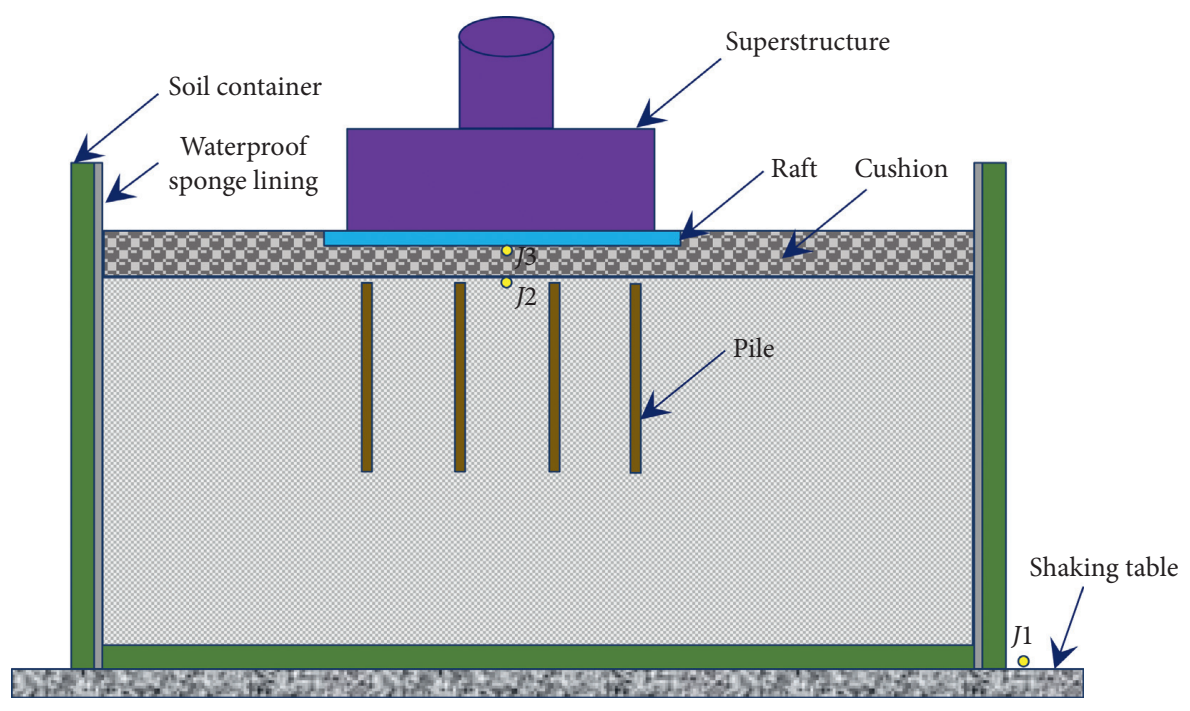

- Acceleration

FIGURE 5: Schematic illustration of the test model and measurement point configuration (acceleration was measured at three points).

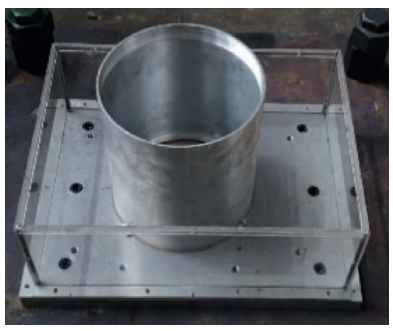

(a)

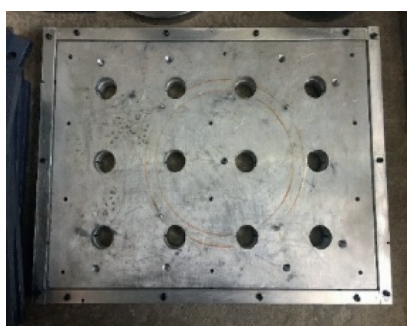

(b)

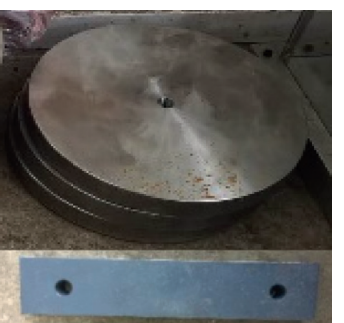

(c)

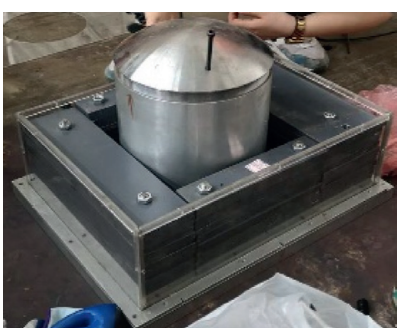

(d)

Figure 6: Superstructure-raft model. (a) Superstructure container. (b) Raft. (c) Mass blocks. (d) Integrated superstructure-raft structure.

Figure 7(c). Figure 7(d) shows the completed test model. Table 3 lists the parameter settings for the series of tests.

To investigate the seismic isolation effect of the clay layer and the gravel cushion, the accelerations at the specimenmounting table surface, the clay layer surface, and the gravel cushion surface were measured for acceleration response analysis. Acceleration data were measured using TST120A500 acceleration transducers and were collected using a TST3000 dynamic signal test and analysis system. Figure 5 shows the configuration of measurement points.

\section{Test Results}

3.1. Analysis of Acceleration Time History. Figure 8 shows the acceleration time histories of the three gravel cushions built with the differently graded aggregates (single-sized, two-sized, and 


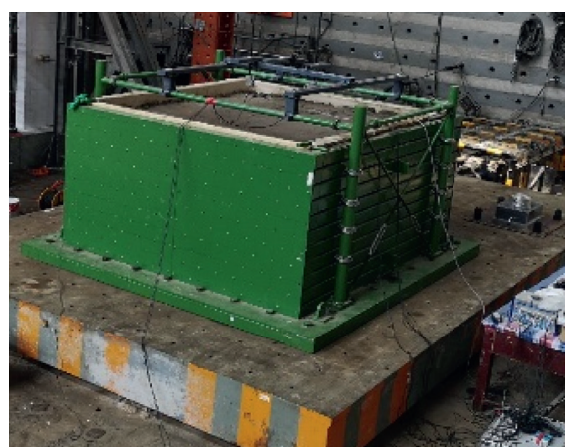

(a)

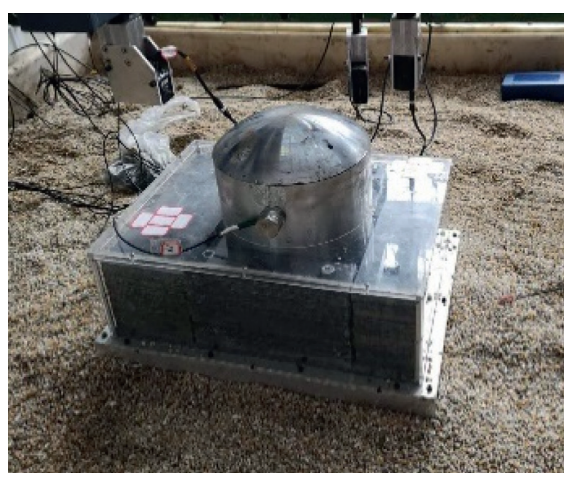

(c)

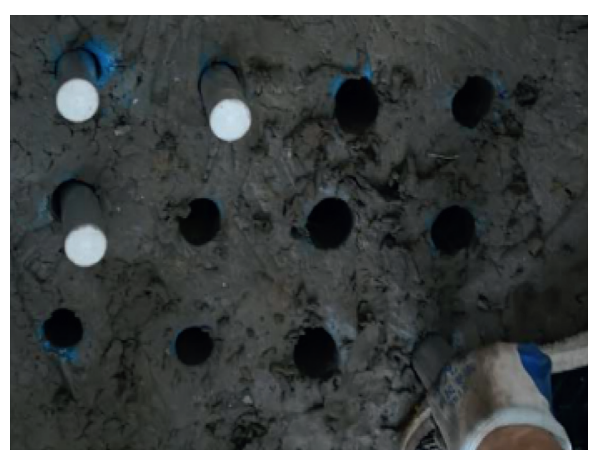

(b)

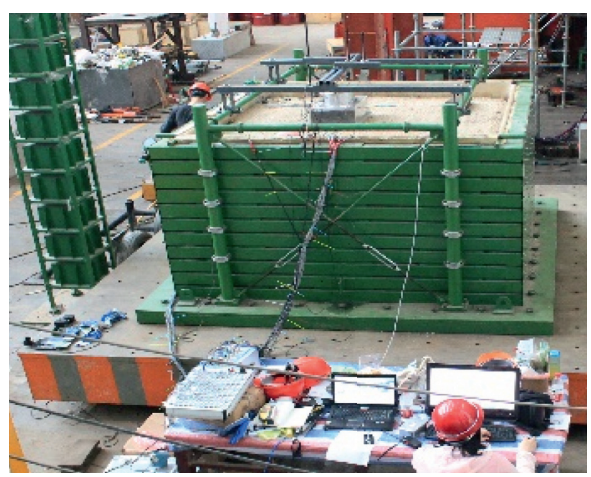

(d)

Figure 7: Test model construction procedure. (a) Clay casting. (b) Holes reserved for mounting piles. (c) Gravel, superstructure-raft. (d) Completed model.

TABle 3: Parameter settings for shaking table tests (El Centro seismic waves).

\begin{tabular}{|c|c|c|c|}
\hline No. & Peak acceleration of shaking table $(\mathrm{g})$ & Gravel aggregate gradation & Buried depth of gravel cushion \\
\hline S-1-1 & \multirow{6}{*}{0.1} & \multirow{2}{*}{ Single-sized } & Beneath raft \\
\hline S-1-2 & & & Above raft \\
\hline D-1-1 & & \multirow{2}{*}{ Two-sized } & Beneath raft \\
\hline D-1-2 & & & Above raft \\
\hline C-1-1 & & \multirow{2}{*}{ Continuous gradation } & Beneath raft \\
\hline C-1-2 & & & Above raft \\
\hline S-2-1 & \multirow{6}{*}{0.2} & \multirow{2}{*}{ Single-sized } & Beneath raft \\
\hline S-2-2 & & & Above raft \\
\hline D-2-1 & & \multirow{2}{*}{ Two-sized } & Beneath raft \\
\hline D-2-2 & & & Above raft \\
\hline C-2-1 & & \multirow{2}{*}{ Continuous gradation } & Beneath raft \\
\hline$C-2-2$ & & & Above raft \\
\hline S-3-1 & \multirow{6}{*}{0.3} & \multirow{2}{*}{ Single-sized } & Beneath raft \\
\hline S-3-2 & & & Above raft \\
\hline D-3-1 & & & Beneath raft \\
\hline $\mathrm{D}-3-2$ & & Two-sized & Above raft \\
\hline C-3-1 & & Continuous orad & Beneath raft \\
\hline $\mathrm{C}-3-2$ & & Continuous gradation & Above raft \\
\hline
\end{tabular}

continuous) under input El Centro seismic waves with three different peak accelerations $(0.1 \mathrm{~g}, 0.2 \mathrm{~g}$, and $0.3 \mathrm{~g})$. The acceleration time histories at the bottom of the clay layer largely overlapped and were overall highly consistent with those at the top of the clay layer. The pile-reinforced soil did not exhibit a significant acceleration amplification or vibration filtering effect. In comparison, the peak acceleration time at the top of the gravel cushion was lower than that at the bottom of the gravel cushion, which indicates that the gravel cushion had a seismic isolation effect. In addition, an increase in the peak acceleration produced an increase in the seismic isolation effect. This finding is consistent with the literature [21].

Notably, the effect of the buried depth of the cushion on the seismic isolation effect did not exhibit a consistent pattern. As shown in Figure 8(c), under input seismic waves with a $0.3 \mathrm{~g}$ peak acceleration, the three cushions had a better seismic 

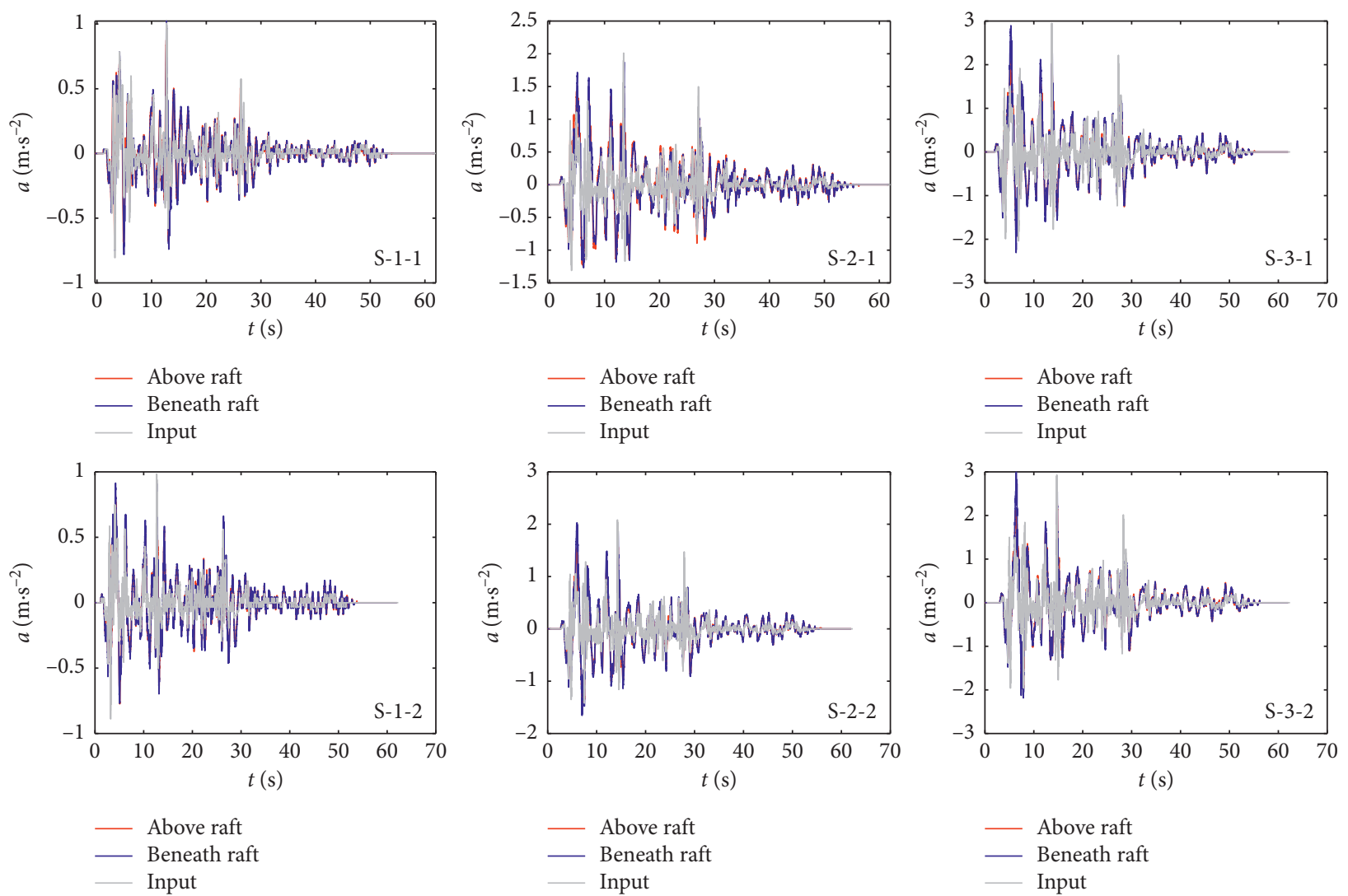

(a)
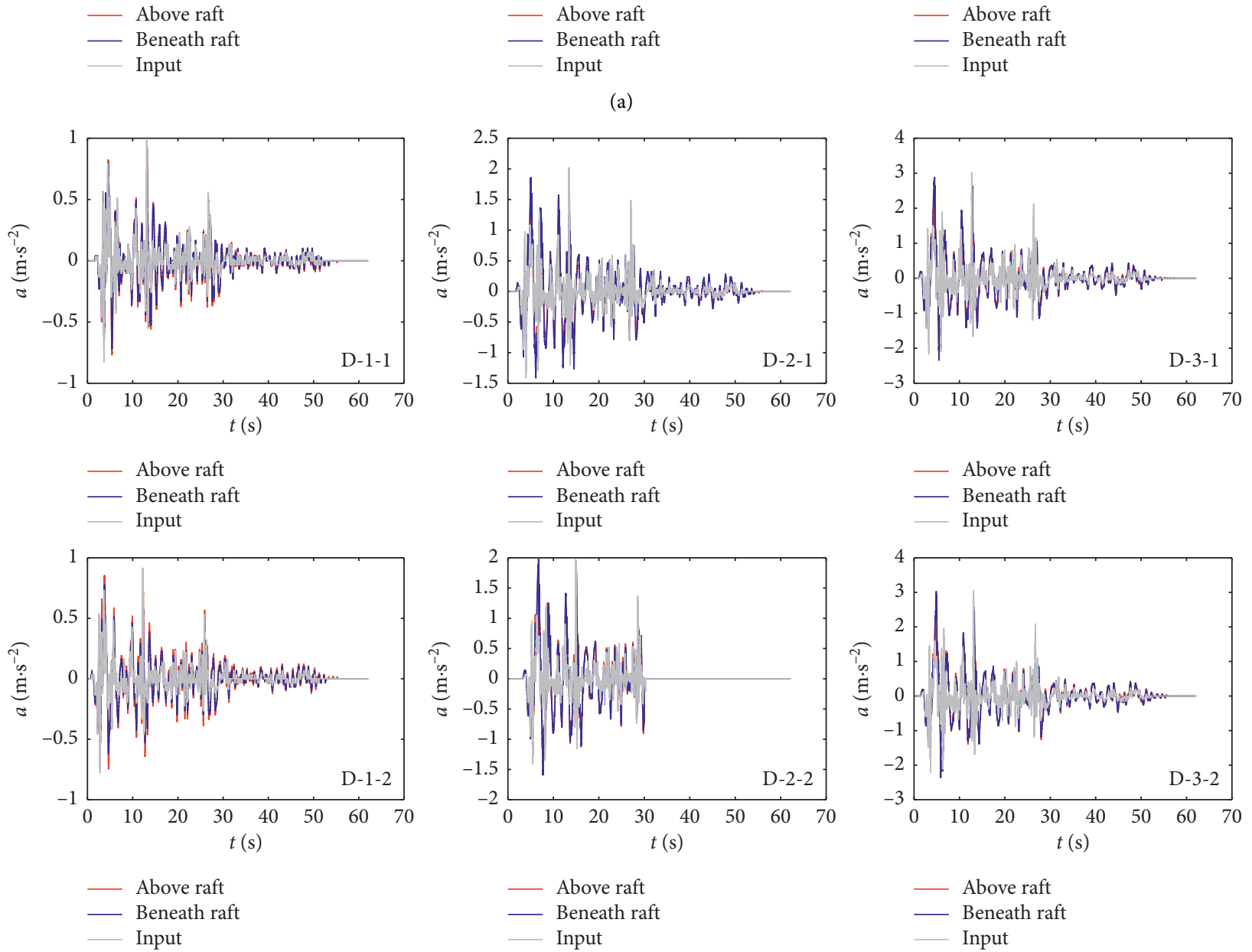

(b)

Figure 8: Continued. 

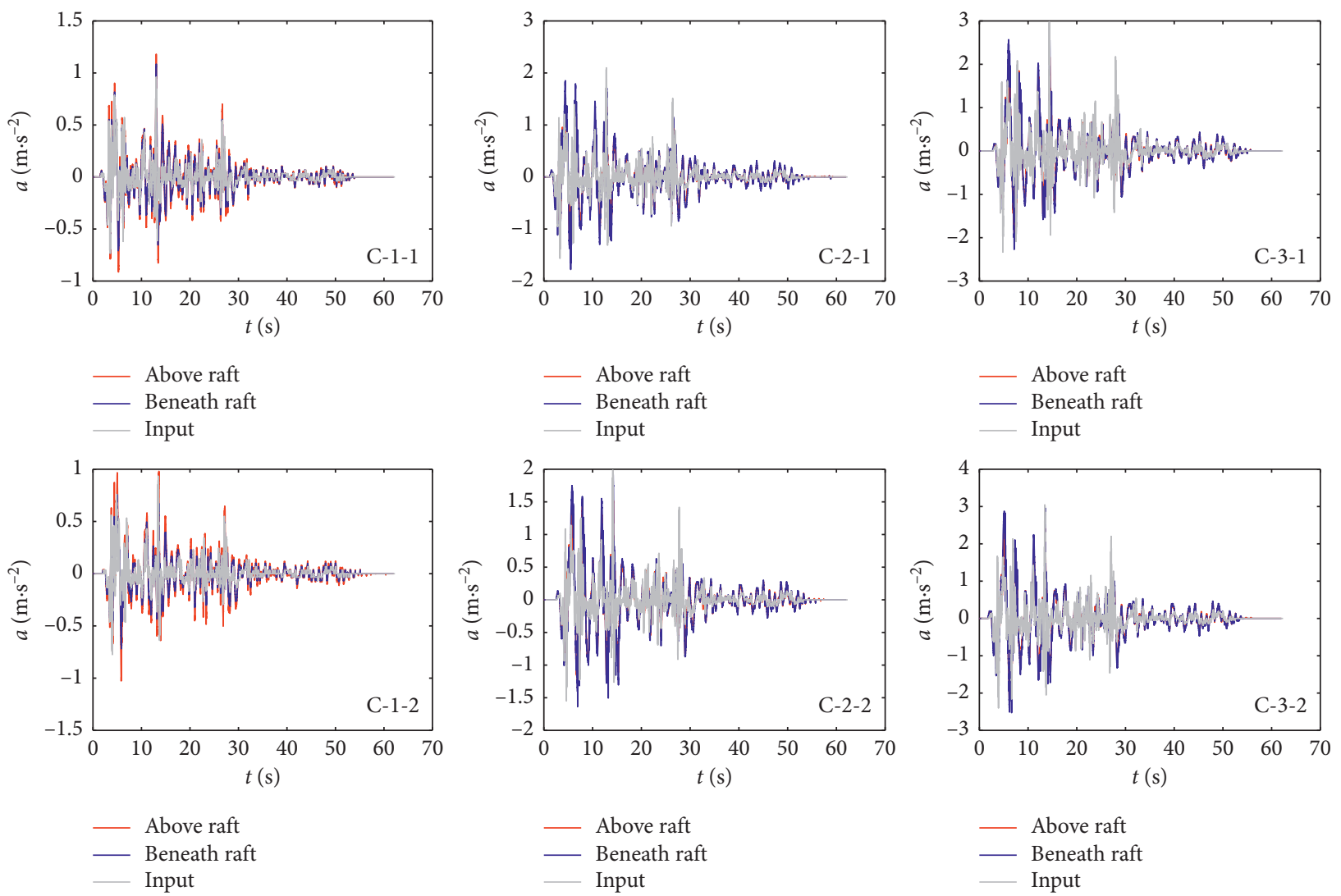

(c)

Figure 8: Acceleration time histories of the clay layer and gravel cushion. (a) Single-sized aggregate gravel cushion. (b) Two-sized aggregate gravel cushion. (c) Continuously graded aggregate gravel cushion.

isolation effect when placed above the raft than when placed beneath the raft. The cushions were designed with a small thickness due to the limited capacity of the shaking table. Gravels slid and spread laterally under large seismic forces. When placed above the raft, the cushions had a resistance effect and better maintained the cushion thickness; thus, a greater seismic isolation effect was realized. To determine whether this finding is applicable to real-world engineering, further investigation is required.

A comparative analysis of the acceleration responses of the three gravel cushions showed that, with input seismic waves of any peak acceleration $(0.1 \mathrm{~g}, 0.2 \mathrm{~g}$, or $0.3 \mathrm{~g})$, the single-sized aggregates had a better seismic isolation effect on the cushion than the two-sized and continuously graded aggregates (Figure 8). This finding is consistent with that reported in [13]. In particular, under input seismic waves with a $0.1 \mathrm{~g}$ peak acceleration, the single-sized aggregate gravel cushion had a seismic isolation effect, whereas the cushions built with the two-sized and continuously graded aggregates did not have a notable seismic isolation effect. Therefore, a gravel cushion for foundation seismic isolation purposes should be built with single-sized aggregates.

3.2. Analysis of the Seismic Isolation Effect of the Gravel Cushion. The vibration reduction rate is introduced to investigate the seismic isolation effect of the cushion material and better evaluate the vibration reduction performance of the cushion:

$$
R_{a}=\frac{\left|a_{\mathrm{in}}\right|_{\max }-\left|a_{\mathrm{out}}\right|_{\max }}{\left|a_{\mathrm{in}}\right|_{\max }} \times 100 \%
$$

where $\left|a_{\text {out }}\right|_{\max }$ is the peak output acceleration and $\left|a_{\text {in }}\right|_{\max }$ is the peak input acceleration. The $\left|a_{\text {in }}\right|_{\max }$ and $\left|a_{\text {out }}\right|_{\max }$ of the clay layer are equal to the peak accelerations at the surface of the specimen-mounting table and the top of the clay layer, respectively. The $\left|a_{\text {in }}\right|_{\max }$ and $\left|a_{\text {out }}\right|_{\max }$ of the gravel cushion are equal to the peak accelerations at the bottom of the cushion (top of the clay layer) and the top of the cushion, respectively. The vibration reduction rates of the clay layer and gravel cushion at different parameter settings were computed using equation (1).

As shown in Figure 9, the vibration reduction rate of the clay layer under seismic waves with peak accelerations of $0.1 \mathrm{~g}, 0.2 \mathrm{~g}$, and $0.3 \mathrm{~g}$ varied in the ranges of $-13.54 \%$ $-18.28 \%, 0.51 \%-11.90 \%$, and $-2.05 \%-11.74 \%$, respectively, and had average values of $5.70 \%, 4.38 \%$, and $3.27 \%$, respectively. Because of the reinforcement effect of the rigid piles, as the peak acceleration increased, the vibration reduction rate of the clay layer did not vary much and was near 0 , which indicates that the peak acceleration had minimal effect on the vibration reduction performance of the clay layer. In addition, the peak 


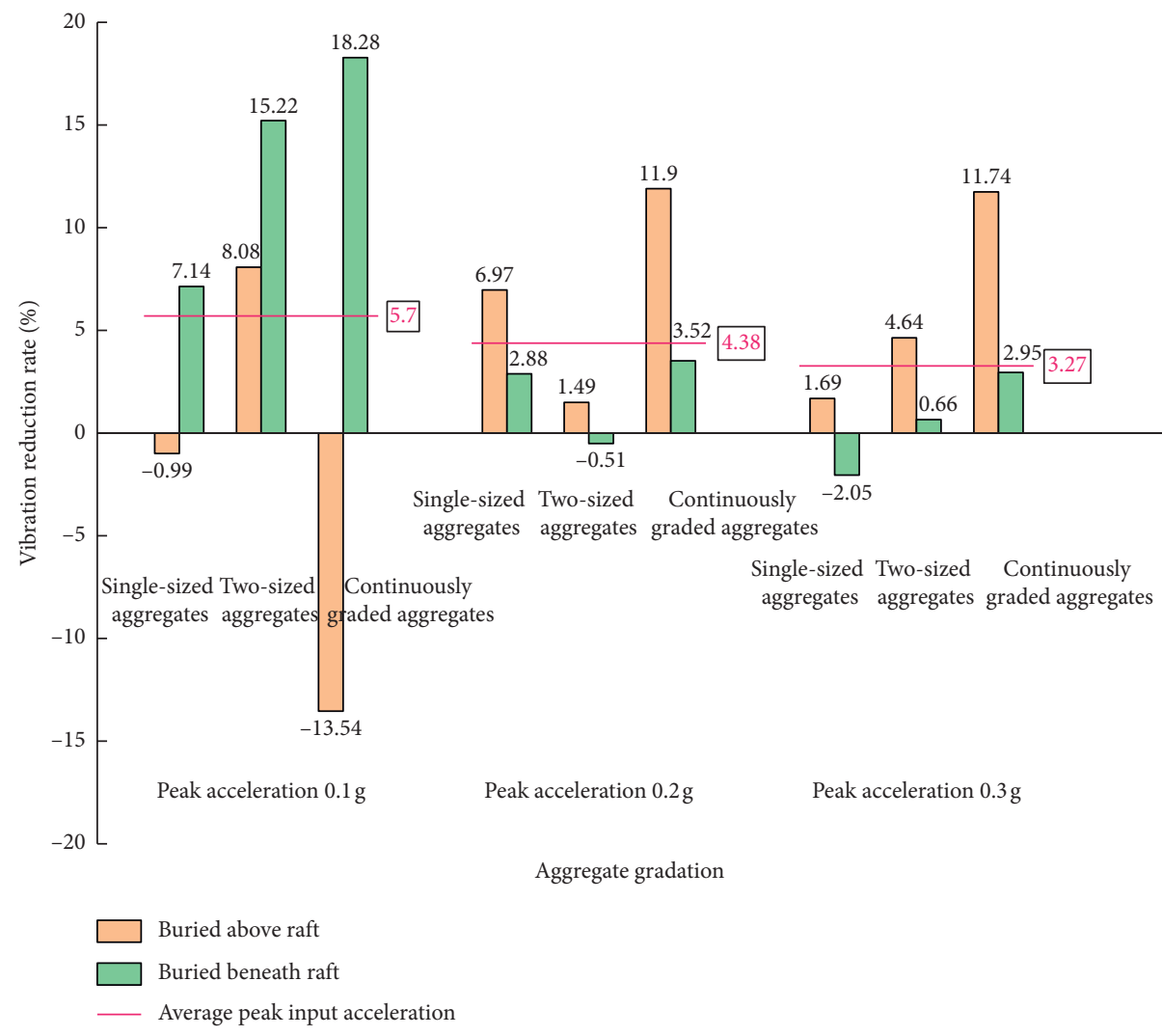

FIGURE 9: Vibration reduction rates of the clay layer at different parameter settings.

accelerations of the seismic waves did not decrease much as they propagated upward from the bottom of the clay layer, which indicates a poor seismic isolation capacity of the clay layer. Literature [22] reported an amplification effect of foundation soil, which is inconsistent with this finding but corroborates our finding that foundation soil did not have a vibration reduction effect.

As shown in Figure 10, the vibration reduction rate of the gravel cushions under input seismic waves with peak accelerations of $0.1 \mathrm{~g}, 0.2 \mathrm{~g}$, and $0.3 \mathrm{~g}$ varied in the ranges of $-8.9 \%-13.73 \%, 10.61 \%-22.77 \%$, and $12.85 \%-24.08 \%$, respectively, with average values of $-0.55 \%, 18.63 \%$, and $17.92 \%$, respectively. The gravel cushions had no seismic isolation effect under input seismic waves with $0.1 \mathrm{~g}$ peak acceleration but had a great damping and a notable seismic isolation effect when this value was $0.2 \mathrm{~g}$ or $0.3 \mathrm{~g}$.

The effect of the buried depth of the gravel cushion on the vibration reduction rate showed no consistent pattern. Under input seismic waves with a $0.3 \mathrm{~g}$ peak acceleration, the gravel cushions had a greater seismic isolation effect when placed above the raft than when placed beneath the raft. When placed above the raft, the single-sized aggregate gravel cushion had the largest vibration reduction rate, followed by the cushions built with the two-sized and continuously graded aggregates.

Under input seismic waves with a $0.1 \mathrm{~g}$ peak acceleration, the single-sized aggregate gravel cushion had a vibration reduction rate of approximately $11.81 \%$, whereas the cushions built with the two-sized and continuously graded aggregates had vibration reduction rates smaller than 0 , which indicates that the last two cushions had no seismic isolation effect. This result can be explained by the following mechanism. An input seismic wave with $0.1 \mathrm{~g}$ peak acceleration causes small ground motion. The cushions built with the two-sized and continuously graded aggregates are denser than the single-sized aggregate cushion and undergo less elastoplastic deformation, so they transmit the seismic energy and shear force that are produced by the horizontal seismic forces to the raft and have no damping/dissipation effect [23].

Under input seismic forces with a $0.2 \mathrm{~g}$ peak acceleration, the three gravel cushions had slightly different seismic isolation effects and had average vibration reduction rates of approximately $18.63 \%$. Under input seismic waves with a 0.3 g peak acceleration, the single-sized aggregate gravel cushion had the greatest vibration reduction effect and the largest average vibration reduction rate $(22.39 \%)$, followed by cushions built with continuously graded aggregate (average vibration reduction rate $\approx 17.53 \%$ ) and two-sized aggregates (average vibration reduction rate $\approx 13.85 \%$ ). Under input seismic waves with peak accelerations of $0.2 \mathrm{~g}$ and $0.3 \mathrm{~g}$, the three gravel cushions had average vibration reduction rates of approximately $18.63 \%$ and $17.92 \%$, respectively, and had a maximum vibration reduction rate of $24.08 \%$ at some parameter settings, which indicates that the cushions had a seismic isolation effect. This effect can be explained by the following mechanism. Input seismic waves with peak accelerations of $0.2 \mathrm{~g}$ and $0.3 \mathrm{~g}$ produce large ground motion. 


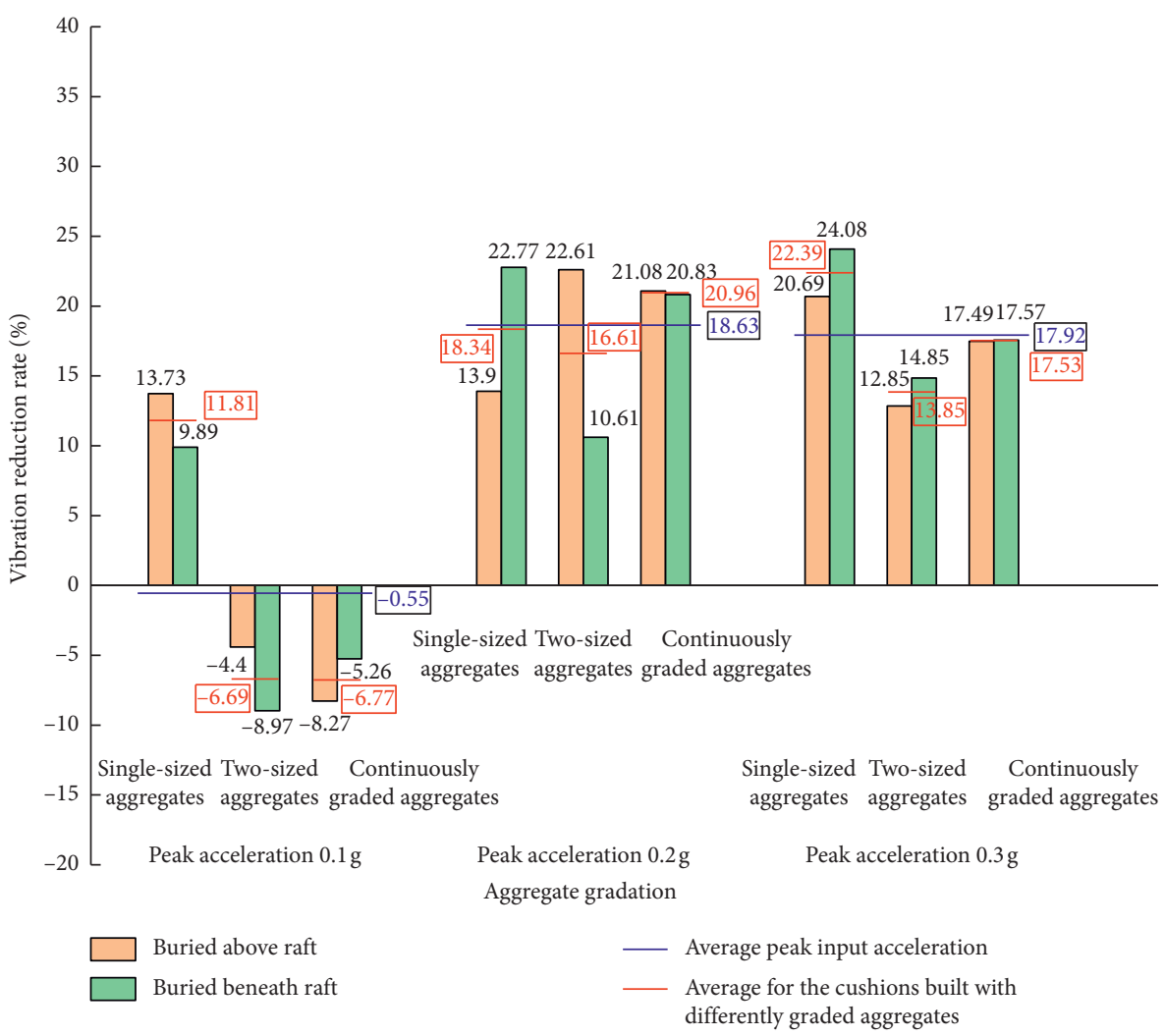

Figure 10: Vibration reduction rates of cushion at different parameter settings.

The gravel cushions undergo elastoplastic or plastic deformation and do not transfer all the horizontal shear forces upward; thus, they dissipate part of the seismic energy and effectively reduce the seismic energy transmitted upward $[23,24]$.

The single-sized aggregate gravel cushion had a better seismic isolation effect than the cushions built with the twosized and continuously graded aggregates. Therefore, for nuclear power plants built in seismic zones, gravel cushions should be built with single-sized aggregates, provided that the required bearing capacity is satisfied.

\subsection{Empirical Model for Vibration Reduction Rate Prediction.} Test data of the gravel cushions at different parameter settings were regressed to determine the relationship between the vibration reduction rate and the peak input acceleration. Thereby, an empirical model was developed for predicting the vibration reduction rate of a gravel cushion:

$$
R_{a}=1-\frac{\left(\left|a_{i n}\right|_{\text {max }} / g\right)}{\alpha+\beta\left(\left|a_{i n}\right|_{\text {max }} / g\right)},
$$

where $\alpha$ is a parameter of the model and $1-1 / \beta$ is the ultimate vibration reduction rate $R_{a \text {,ult }}$ under input seismic waves with $0.3 \mathrm{~g}$ peak acceleration. This value represents the upper limit of the seismic isolation capacity of a gravel cushion.

Figure 11 shows the relationship between the vibration reduction rate of the gravel cushion and the peak input acceleration. The fitted curve of the whole working condition in Figure 11 shows the seismic isolation effect of the gravel cushion by general trend. Table 4 gives the average values as well as the upper and lower limits of the $95 \%$ confidence intervals of the parameters of the fitting curve for the test data obtained at different parameter settings. As shown in the figure, the seismic isolation capacity of the gravel cushion fell in the $95 \%$ confidence interval, which confirms that equation (2) has a high goodness of fit and can well reflect the trend that the vibration reduction rate of the gravel cushion increases with the peak input acceleration. Under seismic waves with $0.3 \mathrm{~g}$ peak acceleration, the ultimate vibration reduction rate $R_{a \text {,ult }}$ varied in the range of $20.44 \%$ to $31.33 \%$. The seismic isolation capacity of a cushion for a particular nuclear power plant can be estimated by using equation (2) and Table 5. An appropriate strategy for the practice application of Table 5, from the perspective of safety reserve, is to take the lower limit of the $95 \%$ confidence intervals.

Figure 11 shows the fitted relationship between the vibration reduction rate of the three gravel cushions and the peak input acceleration. The comparison on seismic isolation effect between the three gravel cushions is carried out with the fitted curves of the three single working conditions in Figure 11. The fitted curve for the single-sized aggregate gravel cushion is located at the top, the two-sized aggregate cushion is located at the bottom, and the cushion built with continuously graded aggregates is located between them, which indicates that the single-sized aggregates contribute to a larger seismic isolation capacity than the other two 


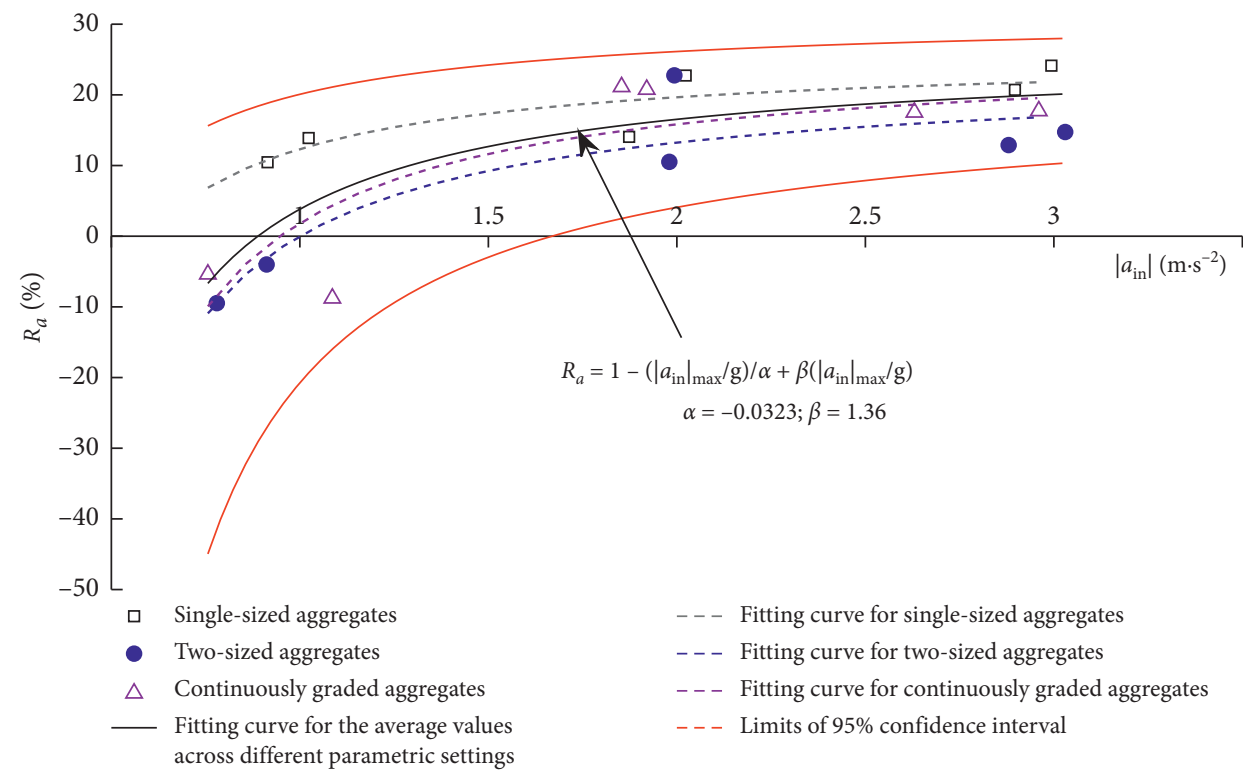

FIGURE 11: Relationships between the vibration reduction rate of the gravel cushion and the peak input acceleration.

TABLE 4: Fitted parameters of the average vibration reduction rate of gravel cushions at different parameter settings.

\begin{tabular}{lccc}
\hline Parameter & $\alpha \times 10^{-2}$ & $\beta$ & $R_{a, \text { ult }}=1-(1 / \beta)(\%)$ \\
\hline Fitted value & -3.23 & 1.36 & 26.29 \\
Upper limit of 95\% confidence interval & -4.37 & 1.26 & 20.44 \\
Lower limit of 95\% confidence interval & -2.09 & 1.46 & 31.33 \\
\hline
\end{tabular}

Note. Regression coefficient of correlation is 0.8182 .

TABLE 5: Regression parameters for the vibration reduction rates of the three gravel cushions.

\begin{tabular}{lcccc}
\hline Cushion type & $\alpha \times 10^{-2}$ & $\beta$ & $R_{a \text {,ult }}=1-(1 / \beta)(\%)$ & Correlation coefficient \\
\hline Single-sized aggregates & -2.12 & 1.35 & 25.86 & 0.93 \\
Two-sized aggregates & -3.11 & 1.31 & 23.39 & 0.89 \\
Continuously graded aggregates & -3.45 & 1.36 & 26.33 & 0.87 \\
\hline
\end{tabular}

aggregates. The prediction is consistent with the observations. Table 5 shows the fitting parameters for the vibration reduction rate of the three gravel cushions. For seismic waves with a $0.3 \mathrm{~g}$ peak acceleration, the cushions built with the single-sized aggregates, two-sized aggregates, and continuously graded aggregates had ultimate vibration reduction rates of $25.86 \%, 23.39 \%$, and $26.33 \%$, respectively. Thus, it can be speculated that under input seismic waves with a 0.3 g peak acceleration, gravel cushions built with single-sized and continuously graded aggregates have close ultimate vibration reduction rates. Notably, as the peak input acceleration decreased, the vibration reduction rate of the single-sized aggregate gravel cushion decreased more slowly and was sustained at a certain level even at a low-peak input acceleration.

Figure 12 compares the testing results of the seismic isolation performance of the gravel cushions obtained in this study and those reported in the literature. A $5 \mathrm{~cm}$-thick compacted gravel cushion is not inferior to a compacted sand cushion with a thickness of $20 \mathrm{~cm}-30 \mathrm{~cm}$ in terms of the seismic isolation performance but is inferior to a $40 \mathrm{~cm}$-thick compacted sand cushion and 70\% compacted sand cushion, particularly under input seismic waves with a peak input acceleration of $0.1 \mathrm{~g}$. The seismic isolation performance of a gravel cushion is poorer than that of a sand cushion under some parameter settings and is related to the compactness and aggregate gradation. In comparison, the vibration reduction capacity of a sand cushion is not greatly affected by the peak acceleration variation. The sand cushion has a vibration reduction effect even under input seismic waves with $0.1 \mathrm{~g}$ peak acceleration but is susceptible to sand liquefaction. Therefore, discretion should be exercised when using sand cushions in composite foundations for nuclear power plants.

These analyses show that the seismic isolation performance of a cushion is related to the properties of the material used as well as the thickness and compactness of the cushion. The thicker and less compacted the cushion is, the better the seismic isolation performance is. For a given cushion thickness, the gravel cushions used in this study had better seismic isolation performance than the reported values $[13,14]$. 


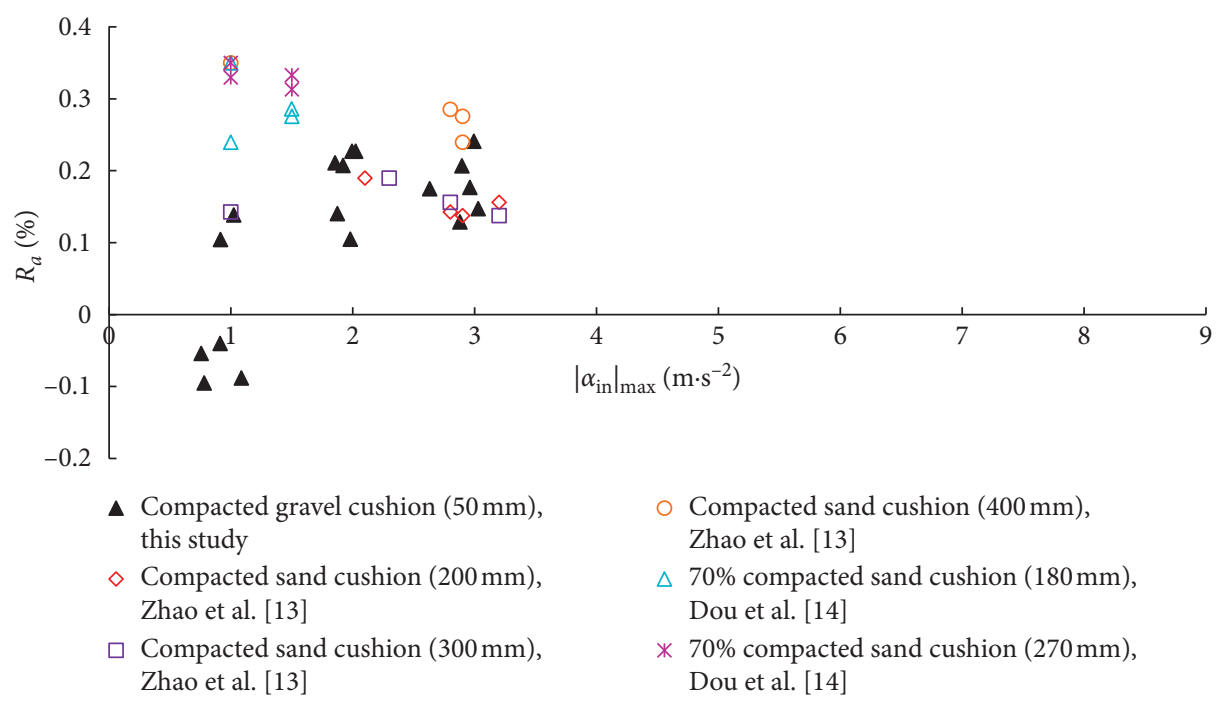

FIgURE 12: Comparison of the seismic isolation performance of the cushions used in this study and reported in the literature.

\section{Conclusions}

(1) A gravel cushion in the composite foundation of a nuclear power plant can effectively reduce the seismic energy that is transmitted upward from the pile-soil composite foundation. Under input seismic waves with peak accelerations of $0.2 \mathrm{~g}$ and $0.3 \mathrm{~g}$, the gravel cushion had a seismic isolation effect and average vibration reduction rates of $18.63 \%$ and $17.53 \%$, respectively. The vibration reduction rate reached $24.08 \%$ with some parameter settings.

(2) A comparison of the seismic isolation performance of the three gravel cushions built with differently graded aggregates showed that the single-sized aggregates contributed to the best seismic isolation performance, followed by the continuously graded and two-sized aggregates. In particular, the singlesized aggregate gravel cushion had a vibration reduction rate of approximately $11.81 \%$ even under input seismic waves with a $0.1 \mathrm{~g}$ peak acceleration. Therefore, single-sized aggregate gravel cushions are the best option for nuclear power plant foundations with a high requirement for seismic isolation, provided that the required bearing capacity is satisfied.

(3) An empirical model is proposed for predicting the vibration reduction rate (which is measured as the ultimate vibration reduction rate) of a gravel cushion. The model well reflected the trend that the vibration reduction rate of the gravel cushion increased with the peak input acceleration. Under input seismic waves with a $0.3 \mathrm{~g}$ peak acceleration, the ultimate vibration reduction rate $R_{a \text {,ult }}$ of the gravel cushions varied in the range of 20.45 to $31.3 \%$. As the peak seismic acceleration decreased, the vibration reduction rate of the single-sized aggregate gravel cushion decreased more slowly than that of the other two cushions and remained above a certain level, and the gravel had a certain seismic isolation capacity even under input seismic waves with a $0.1 \mathrm{~g}$ peak acceleration.

(4) A $5 \mathrm{~cm}$-thick compacted gravel cushion had a seismic isolation capacity that is approximately equal to that of a compacted sand cushion with a thickness of $20-30 \mathrm{~cm}$. Under input seismic waves with a $0.1 \mathrm{~g}$ peak acceleration, the gravel cushion had a smaller seismic isolation capacity than the sand cushion. However, we speculate that when the cushion thickness is increased to a certain level, a gravel cushion has a desirable seismic isolation capacity even under input seismic waves with a $0.1 \mathrm{~g}$ peak acceleration.

(5) The effect of gravel cushion thickness on the seismic isolation performance of composite foundations needs further investigation. In addition, this seismic isolation technology may increase the displacement of the seismic-isolating cushion while reducing the acceleration response of the structure, which is a topic worthy of further investigation.

\section{Data Availability}

Some data used during the study are available from the corresponding author upon request.

\section{Conflicts of Interest}

The authors declare that they have no conflicts of interest regarding the publication of this paper.

\section{Acknowledgments}

This funding was provided by the State Key Laboratory of Frozen Soil Engineering (Grant no. SKLFSE201907), National Natural Science Foundation of China (no. 51678145), National Key R\&D Program of China (no. 2018YFC1505300), National Major Scientific Instruments 
Development Project of China (no. 41627801), and Key Research and Development Projects in Hainan Province (no. ZDYF2017100).

\section{References}

[1] GB50267-2019, Standard for Seismic Design of Nuclear Power Plants (GB50267-2019), Ministry of Housing and UrbanRural Development of the China, Beijing, China, 2019.

[2] X. Pan, Research on Overall Seismic Performance Analysis of Rigid Pile Composite Foundation-Foundation -Upper Structure, Zhengzhou University, Zhengzhou, China, 2016.

[3] D. Liu, G. Zheng, J. Liu, and J. Li, "Experimental study to reduce differential settlements of raft of composite foundation with rigid piles," Chinese Journal of Geotechnical Engineering, vol. 04, pp. 517-523, 2007.

[4] Z. Guo, Z. Wang, and Z. Yang, "Field study of reactions of rigid pile composite foundation for high-rise building," Rock and Soil Mechanics, vol. 30, no. 01, pp. 163-168, 2009.

[5] J. Tao, S. Liang, and W. C. GongWeiming, "Study on bearing behavior of composite foundation with rigid pile for high-rise buildings," Journal of Southeast University (Natural Science Edition), vol. 39, no. S2, pp. 238-245, 2009.

[6] J. Tao, S. Liang, Y. Fan et al., "Field tests on high-bearing composite foundation with plain concrete piles," Chinese Journal of Geotechnical Engineering, vol. 34, no. 04, pp. 693-700, 2012.

[7] G. Zheng and H. Zhou, "State-of-the-Art review of ultimate bearing capacity and stability of composite foundations," Journal of Tianjin University (Science and Technology), vol. 53, no. 07, pp. 661-673, 2020.

[8] Y. Chi, E. Song, H. Jin, and W. Gao, "Experimental study on stress distribution of composite foundation with rigid piles," Rock and Soil Mechanics, vol. 24, no. 3, pp. 237-241, 2003.

[9] J. Yang, M. Yang, and R. Luo, "Dynamic centrifuge model test of composite foundation with rigid pile in soft clay," Chinese Journal of Underground Space and Engineering, vol. 15, no. 02, pp. 381-386+401, 2019.

[10] V. J. Sharma, S. A. Vasanvala, and C. H. Solanki, "Behaviour of cushioned composite piled raft foundation under lateral forces," Indian Geotechnical Journal, vol. 45, no. 1, pp. 89-97, 2015.

[11] H. Hazarika, E. Kohama, and T. Sugano, "Underwater shake table tests on waterfront structures protected with tire chips cushion," Journal of Geotechnical and Geoenvironmental Engineering, vol. 134, no. 12, pp. 1706-1719, 2008.

[12] W.-B. Tu, M.-S. Huang, and X.-Q. Gu, "Dynamic behavior of laterally loaded caisson foundations based on different cushion types: an experimental and theoretical study," Journal of Zhejiang University-Science A, vol. 21, no. 7, pp. 565-579, 2020.

[13] S. Zhao, Y. Dou, R. Guo et al., "An experimental study of isolating properties of sand cushion under the foundation by shaking table," Journal of Hebei University of Technology, vol. 03, pp. 92-97, 2005.

[14] Y. Dou, X. Liu, S. Zhao et al., "An experimental study of isolating properties of sand cushion," Journal of Building Structures, vol. 01, pp. 125-128, 2005.

[15] X. Liu, J. Wang, Y. Dou et al., "The study of seismic response of sand cushion in different thickness and different foundation pressure," Journal of North China Institute of Astro Nautic Engineering, vol. 14, no. 2, pp. 7-10, 2004.

[16] X.-L. Han, Y.-K. Li, J. Ji, and F. Luo, "Effects of site factors on the performance of rigid-pile composite foundation in tall buildings," The Open Civil Engineering Journal, vol. 8, no. 1, pp. 71-77, 2014.

[17] X. Han, Y. Li, J. Ji, J. Ying, W. Li, and B. Dai, "Numerical simulation on the seismic absorption effect of the cushion in rigid-pile composite foundation," Earthquake Engineering and Engineering Vibration, vol. 15, no. 2, pp. 369-378, 2016.

[18] X. Zhao, Q. Zhang, Q. Zhang et al., "Numerical study on seismic isolation effect of gravel cushion," in Proceedings of the International Conference on Discrete Element Methods, Springer, Singapore, November 2017.

[19] Y. Li, X. Han, K. Galal, and J. Ji, "Experimental study on the shear behavior of the interface between cushion materials and the concrete raft," Earthquake Engineering and Engineering Vibration, vol. 17, no. 1, pp. 165-178, 2018.

[20] S. Wu, E. Song, H. Liu et al., "Shaking table test of composite foundation with rigid pile," Chinese Journal of Geotechnical Engineering, vol. 11, pp. 99-102, 2005.

[21] F. Liu, M. Wu, and L. Jing, "Experimental study on the isolating performance of a new reinforced rubber-sand mixture composite cushion," Journal of Vibration and Shock, vol. 38, no. 22, pp. 184-189+197, 2019.

[22] Ma Kang and J. Pei, "Study of dynamic interaction between pile-raft foundation and soft clay by centrifuge model tests," Chinese Journal of Rock Mechanics and Engineering, vol. 30, no. 07 , pp. $1488-1495,2011$.

[23] X. Han, C.-A, Xiao, and J. Ying, "Dynamic elastoplastic analysis of interaction system of composite foundation-raftsuperstructure under earthquake action," Rock and Soil Mechanics, vol. 34, no. 03, pp. 762-768, 2013.

[24] Y. Liang, Z. Tian, and J. Li, "ANSYS/LS-DYNA explicit integration procedures simulation of the foundation gravel layer to improve the seismic capacity of buildings," Journal of Inner Mongolia University of Science and Technology, vol. 28, no. 04, pp. 354-357, 2009. 